\title{
A poética da fome e a escrita da precariedade: sobre Carolina Maria de Jesus
}

\author{
Lívia Natália*
}

O que sempre invejei nos livros foi o nome do autor.

Carolina Maria de Jesus

\section{As primeiras páginas do diário}

A maioria de nós jamais saberá o impacto que a fome provoca sobre o corpo, a dignidade e a subjetividade de um ser humano. Ouvimos falar, muitas vezes há algum caso na família, mas, para nós, afiliados a uma cultura letrada (ABREU, 2006) ler a miséria escrita nas páginas de um livro nos assalta naquele espaço em que antes reservamos ao sublime. Para os estudiosos de literatura brasileira, os retratos de vivência subumana fincaram-se como instantâneos à época dos romances de 3o, quando a fome, a miséria e a vulnerabilidade social foram ostensivamente representadas. Se estávamos já familiarizados com tais questões em narrativas construídas 25 anos antes do Quarto de despejo (1993), de Carolina Maria de Jesus, em que aqueles instantâneos de miséria por ela apresentados nos surpreenderam? Por que tamanha mobilização ${ }^{1}$ em torno do seu diário?

A resposta me parece bastante simples: os romances de 30, apesar de abrirem uma visão sobre as condições aqui descritas, eram textos tomados e produzidos como ficcionais e, assim sendo, abranda-se o impacto destes no ser e estar cotidiano. Pela própria ideia que se tem de literatura como algo que, ao se produzir em texto ficcional, escaparia à referencialidade (a partir de então atrelada ao discurso histórico ou jornalístico), e de que a porta de entrada no texto literário seria o pacto ficcional estabelecido pelo leitor ao se permitir crer no que quer que trouxesse o texto. Em outras palavras, o texto ficcional seria um engodo à realidade, seu trabalho seria o de, constantemente, embotá-la, ludibriá-la e os romances de 3o, por mais que tivessem um apelo ao representar os escamoteados da composição da paisagem nacional, ainda assim eram textos ficcionais.

\footnotetext{
Doutora em Teorias e Crítica da Literatura e da Cultura e professora da Universidade Federal da Bahia (UFBA), Salvador, BA, Brasil. E-mail: livianataliass@gmail.com

1 Amplamente conhecida por nós, através dos registros das inúmeras reedições do citado livro e de sua tradução para mais de dez idiomas, isto entre as décadas de 1950 e 1960.
} 
Esta leitura quase superficial do poder representacional da literatura tem uma história. Desde Aristóteles, fazer literatura é escrever um texto que se negocia com a referencialidade, escrevendo, portanto, não necessariamente o que foi, mas o que poderia ter sido, segundo a conveniência e a necessidade. Ou ainda, para os intérpretes dele, seria fazer um texto que remeta a si mesmo, ou seja, a literatura não busca referencialidade externa, por ser um jogo de linguagem, sua representação só faria sentido dentro do próprio texto, seria, portanto, autorreferente. Então, um texto de um diário mobiliza estas fronteiras inicialmente estabelecidas para a literatura: ele é um jogo de linguagem, uma vez que brinca com ela - como no caso dos diários de Carolina - ao encenar diálogos, ter momentos poéticos, ser descritivo e performativo e, por outro lado, ser incessantemente referencial; ele se registra por datas, anos, contextos e situações acontecidas. Ou seja, o diário é outra categoria literária.

Numa leitura mais apressada, poderíamos aproximar o diário da autobiografia. No entanto, Philippe Lejeune (2008), um dos maiores estudiosos de diários e autobiografias do mundo, afirma:

Uma entrada num diário é o que foi escrito num certo momento, na mais absoluta ignorância quanto ao futuro, e cujo conteúdo não foi com certeza modificado. Um diário mais tarde modificado ou podado talvez ganhe algum valor literário, mas terá perdido o essencial: a autenticidade do momento. Quando soa a meia-noite, não posso mais fazer modificações. Se o fizer, abandono o diário para cair na autobiografia (LeJEune, 2008).

Ou seja, a temporalidade marcada do diário e a sua fidelidade às 24 horas do dia fazem com que ele seja um texto relativamente estável, não pode receber alterações uma vez que estas já seriam uma interpretação. A força do diário está no seu poder de verdade, no seu entranhamento temporal, na sua capacidade de dizer do que aconteceu. Todo diário, em superfície, nega a ficcionalização. Digo em superfície seguindo o que nos diz Derrida (2005, p. 7) sobre o texto que, segundo ele, "só é um texto se ele oculta ao primeiro olhar, ao primeiro encontro, a lei da sua composição e a regra do seu jogo". Não podemos, como estudiosos da literatura, crer que tudo aquilo que se registra num diário já não seja, per se, uma interpretação do que se viveu. O diário almeja o acontecido, mas toda narração transborda a vivência, sendo, de imediato, uma interpretação desta.

Os rituais de escrita de diário são antigos, segundo Foucault (1992), recuperam o século II d. C. Quando as pessoas registravam não o seu cotidiano, mas frases, descrições de cena e lições aprendidas no decorrer do dia como forma de, num momento posterior, retirar dali um aprendizado, um ensinamento sobre como se comportar perante as eventualidades da vida. Estas pessoas eram copistas, não havia nelas o hábito da interpretação ou análise do seu dia ou do seu cotidiano no decorrer da escrita. Ou seja, apesar da constante vulgarização do termo "escrita de si”, as primeiras vezes em que este gesto foi feito, nada ou quase nada se escrevia 
rigorosamente sobre si, mas, muito mais para si ou para o outro, sempre com uma função de aprendizagem, aconselhamento ou autoanálise. Reforçando esta ideia, voltamos a Lejeune que afirma que os primeiros diários eram coletivos e públicos: livros de notas, contabilidade, etc. Somente no século XVIII eles passam a funcionar a serviço da pessoa.

Para a análise literária contemporânea, portanto, o aprisionamento da literatura à realidade nasce de uma leitura limitada. Por isto vincularemos o estudo aqui empreendido à crítica biográfica, campo de análise das várias textualidades discursivas que podem ser exercidas pelo escritor, que analisa numa horizontalidade interpretativa cartas, poemas, depoimentos, diários e outros registros produzidos pelo escritor, fazendo cindir a separação entre realidade e ficção, uma vez que, como reflete Eneida Maria de Souza, "a crítica biográfica, ao escolher tanto a produção ficcional quanto documental do autor - correspondência, depoimentos, ensaios, crítica - desloca o lugar exclusivo da literatura como corpus de análise e expande os feixes de relações culturais" (SouzA, 2002, p. 111). Tal estudo inscreve-se esteira dos estudos pós-estruturalistas, e é debitário das reflexões de Nietzsche (2003) sobre a construção do discurso histórico, como sendo uma construção discursiva e interpretativa entre outros; e das reflexões de Barthes (1968/2004) quando questiona a permanência do autor como sombra sobre o seu texto e provoca:

Na escrita moderna, com efeito, tudo está por deslindar, mas nada está por decifrar; a estrutura pode ser seguida, "apanhada" (como se diz de uma malha de meia que cai) em todas as suas fases e em todos os seus níveis, mas não há fundo; o espaço da escrita percorre-se, não se perfura; a escrita faz incessantemente sentido, mas é sempre para o evaporar; procede a uma isenção sistemática do sentido; por isso mesmo, a literatura (mais valia dizer, a partir de agora, a escrita), ao recusar consignar ao texto (e ao mundo como texto) um "segredo", quer dizer, um sentido último, liberta uma atividade a que poderíamos chamar contra-teológica, propriamente revolucionária, pois recusar parar o sentido é afinal recusar Deus e as suas hipóstases, a razão, a ciência, a lei (BARTHEs, 2004).

Esta reflexão é ainda retomada por Foucault (1992), o qual, em seu texto O que é um autor, indaga-nos sobre os limites da noção de autor e obra, o que abre espaço para pensarmos a partir das textualidades, do texto e do escritor. Enfim, a história da crítica biográfica tem um largo espectro de análise, e remonta a pensamentos muito anteriores ao pensamento pós-estrutural, apesar de ser dele debitária.

\section{Subjetividade e escrita: os modos de estetizar a dor}

É preciso conhecer a fome para saber descrevê-la. Carolina Maria de Jesus 
Não adianta falar de fome com quem não passa fome. Carolina Maria de Jesus

O primeiro diário de Carolina, Quarto de despejo (1993), certamente não é uma autobiografia, uma vez que, como vimos, esta exige um distanciamento temporal para que se construa uma análise e uma interconexão de fatos aparentemente díspares. Quarto de despejo choca a sociedade que o recebeu justamente pela sua crueza por não primar pelos efeitos estéticos, por desficcionalizar o relato: ele é um registro, um desabafo, uma análise imediata das parcas condições de vida de uma mulher negra e seus três filhos na favela do Canindé, em São Paulo. A narrativa, pela sua veracidade e pungência, espanta a São Paulo de 1960, época de publicação do livro, e Carolina vira uma superstar, uma pessoa que chamava atenção por onde quer que passasse: autógrafos, fotos, entrevistas, enfim, todo um mundo feito para a sua excepcionalidade.

O que muitos dos leitores de Carolina de Jesus esqueceram é que, dentro de qualquer pensamento sobre o sublime, está também o grotesco: "A arte não produz unicamente o Belo, mas também o feio, o horrível, o monstruoso. Existem obras-primas que apresentam assuntos horríveis, máscaras terrificantes, pesadelos enlouquecedores" (DE BRUYNE, 1930). Sendo assim, seus frágeis estômagos digeriram, com dificuldade, a leitura de Quarto de despejo, que logo se tornou um best-seller. O que havia ali de grotesco, a fome em todas as suas cores, os atingiu, os terrificou, mas nada se moveu. A autora comparecia como ave rara, alguém que poderia dizer de um mundo que lhes era completamente alheio, e a aura de verdade do relato adensava a sensação de proximidade com o mundo de Carolina. Mas não precisamos ir longe para compreender que toda a atenção a ela dispensada se esvairia muito brevemente. Casa de alvenaria e seus textos posteriores não tiveram o mesmo impacto e Carolina morre em 1977, após uma crise asmática, na mesma situação de vulnerabilidade anterior ao sucesso com seus livros.

A já velha análise do título do primeiro diário, através da metáfora do quarto de despejo, em que a sociedade coloca aquilo que pouco lhe importa, ou que pode morrer, relaciona-se com aquilo que Michel Foucault (2008) chama de biopoder, que seria o poder de deixar morrer ou permitir que viva. Sobre esta base funcionam as sociedades ocidentais. Estas pessoas, comumente invisíveis às demais classes, repetem a máxima que afirma que quem come esquece que tem gente que passa fome:

As oito e meia da noite eu já estava na favela respirando o odor dos excrementos que mescla com o barro podre. Quando estou na cidade tenho impressão que estou na sala de visita com seus lustres de cristais, seus tapetes de viludos, almofadas de sitim. E quando estou na favela tenho impressão que sou um objeto fora de uso, digno de estar num quarto de despejo (Jesus, 1993, p. 33). 
Ao compreender pessoas como Carolina como seres menores, invisíveis, inumanos, coloca-se no bojo desta representação a impossibilidade de imaginação, de construção simbólica ou artística.

Certamente isto é uma herança da forma como o corpo da mulher negra foi inserido no universo de representação. Não apenas eram lidas como seres inferiores, destinadas à procriação quase que automática, mas as lides domésticas a elas reservadas parecem ter não só as amoldado àquele espaço, como endossado um aspecto patologizante de seu comportamento: são animais que, uma vez destinados à procriação e submissão, compreendem a vida como uma sucessão de experiências meramente corpóreas, que podem ser resumidas na tríade: trabalho braçal - procriação - sexo. As representações em todos os espaços - seja a literatura, a televisão, as artes em geral ou o discurso que circula nas ruas - devolvemnas continuamente a este lugar. O que é um sintoma de que a colonização mental (FANON, 2008) ainda vigora, a invisibilidade das mulheres que ocupam lugares de produção de valor simbólico, como a literatura, é continuamente subalternizado.

Gayatri Spivak, em seu texto Pode um subalterno falar? (2010), apontando uma limitação na posição de Gilles Deleuze e Michel Foucault acerca da representação do Outro enquanto sujeito descentrado, dedica-se a denunciar que o subalterno não consegue falar por que ele é, sistematicamente, não só silenciado, mas falado pelo outro. Hommi Bhabha (1998) nos apontou a formulação básica desta problemática ao discutir o estereótipo como sendo uma estrutura calcada numa verdade não verificável, na medida em que ela se repete, assegurando seu lugar e valor de verdade, mas jamais se expondo à verificação empírica, sob o risco de provar-se falsa ou insuficiente para dar conta desta alteridade. Por seu turno, Spivak (2010) insere a noção de "sujeitos-efeitos" afirmando que os sujeitos pensados como subalternos são efeitos do discurso que assim os representa. Os discursos hegemônicos se arvoram a representar a mulher, falar por ela e protegê-la, sem, no entanto, estar interessado em ouvi-la. Franz Fanon afirma que os corpos dos negros são, no discurso paternalista etnocêntrico, infantilizados e tratados como crianças desorientadas ou como sujeitos desprovidos de juízo de valor e consciência: "Os negros costumam ser divertidos" (FANON, 2008).

Talvez seja por isto que, entre as missões primeiras da formação de um discurso identitário negro, Franz Fanon (2008) aponte, como pedra de toque, aquilo que ele nomeou de descolonização das mentes. Este processo passa pela assunção de um lugar de fala compreendendo as limitações e estereótipos que repousam sobre estes sujeitos e investindo em subvertê-los. Segundo Osmundo Pinho:

A descolonização intelectual como etapa da emancipação racial e consequente transformação da sociedade como um todo deverá, desse modo, passar pela ação intelectual contra-hegemônica. A emergência de uma crítica subalterna representa assim o trabalho de formação de intelectuais subalternos (2007, p. 90). 
Ao colocar a fome como principal eixo de construção dos seus textos, Carolina de Jesus constrói, a seu modo, uma poética da fome. Ou seja, o seu texto se pauta pelo gesto de estetização da dor, lembrando aqui que o estético não se relaciona com a noção de belo, mas da articulação sublime-grotesco que atravessa toda representação literária.

Dessa forma, comer ou não comer é o caminho de interpretação de mundo da família de Carolina. A fome é o centro da narrativa de Quarto de despejo, e tê-la matado, e escapado, ainda que temporariamente, do círculo vicioso da miséria é o eixo primordial de Casa de alvenaria (1961). Para compreender a travessia subjetiva empreendida nos diários, é preciso ceder a esta estética da fome e da precariedade, da lacuna, da impossibilidade de humanidade: "É que a fome deixa as pessoas neuróticas" (JEsus, 1961, p. 16). Ao se organizar por esta forma de representação, o diário instaura um jogo entre a fome, como lacuna irrepresentável, mas ali insistentemente narrada, a comida, como sendo o único linimento possível, e a escrita, como um poderoso suplemento que viabiliza a análise imediata e a representação de sua miséria cotidiana. Jamais diria que Carolina se alimentava pela escrita, mas a sua entrega ao gesto, ao ritual e à cena da escrita é sintomático da tentativa de, ao falar, mesmo que sendo ouvida apenas pelas instáveis paredes de madeira do seu barraco, reivindicava-se não apenas a possibilidade de existência e humanidade, mas de compreender-se como sujeito desejante: "Ela parava, sentava e começava a escrever. Escrever para ela era uma coisa vital. Era, digamos, quase uma compulsão" (DANTAS, 2014).

\title{
Do despejo à alvenaria: escrita da precariedade
}

\author{
Há de existir alguem que lendo o que eu escrevo dirá... isto é mentira! \\ Mas, as miserias são reais. \\ Carolina Maria de Jesus
}

O diferencial do discurso estético instaurado por Carolina Maria de Jesus em relação a todas as demais representações de miséria e fome, sejam elas nos romances de 1930, nos realistas, em Euclides de Cunha e nos demais discursos de representação do subalterno é que, em Carolina de Jesus, o subalternizado assume lugar de fala. Ele já não é mais um sujeito-efeito do discurso hegemônico, e isto causa uma reordenação das formas de compreensão deste discurso.

Se investigarmos uma pequena amostra dos incontáveis textos que abordam a escrita de Carolina, perceberemos uma dedicação quase que sistemática ao tema da fome como um problema social pungente no Brasil, análises sobre a construção linguística e as possíveis interferências do jornalista Audálio Dantas nas versões finais dos textos, estudos sobre o vigor poético de trechos mais líricos de seus textos; como podemos observar, estudar Carolina é uma seara de muitos caminhos. 
Investimos neste texto em como a escrita de Carolina de Jesus instaura alguma coisa que passamos a chamar aqui de escrita da precariedade, construindo um texto onde os valores estéticos, que comumente aprisionam a literatura no castelo do belo, são repensados no sentido de compreender o feio e o grotesco como elementos que demandam uma representação. A noção de precariedade pode ser instaurada a partir de Carolina de Jesus, como nova categoria literária, atuando como síntese das condições de sua escrita e, ao mesmo tempo, como modus operandi da sua representação de mundo.

O ponto de onde o mundo é olhado, este é o cerne da construção desta escrita da precariedade, a dicção que se inaugura ali, em Quarto de despejo, pode ser equacionada por algumas vias: primeiro por veicular um texto com erros crassos de escrita num livro, objeto máximo da cultura letrada. Desta menção, já temos um deslocamento e um abalo da posição confortável de uma sociedade burguesa comumente cega à diferença e que usa de diversos dispositivos, entre os quais podemos destacar a instituição escolar como um importante aparato que põe em circulação diversos preconceitos associados ao uso pragmático da língua escrita e falada.

No entanto, ainda deste contexto, salvava-se - como detalhe peculiar para estes leitores - a desenvoltura da sua escrita. Daí, chegamos ao segundo ponto. Numa escrita desenvolta, muitas vezes lírica, ocupando o privilegiado espaço da narrativa, a autora apresenta não um romance, mas um diário. Conforme já discutimos aqui, a sensação de referencialidade construída pelo diário impõe uma aproximação desta realidade miserável de Carolina. A crueza da narrativa, a simplicidade de equacionar, em texto, uma vivência quase intransponível por meio das palavras dão a esta escrita uma capacidade de, para ela, digerir o sofrimento cotidiano, e, para os seus leitores, de confrontar-se com uma narrativa desconcertante:

12 de Junho eu deixei o leito as 3 da manhã porque quando a gente perde o sono começa a pensar nas miserias que nos rodeia. [...] Deixei o leito para escrever. Enquanto escrevo vou pensando que resido num castelo cor de ouro que reluz na luz do sol. [...] É preciso criar este ambiente de fantasia para esquecer que estou na favela (JEsus, 1993, p. 52).

Temos aqui um terceiro traço da escrita da precariedade investida por Carolina, o gesto da escrita como sublimação do sofrimento. No entanto, não é uma sublimação que apague, desconstrua ou isole a dor. Esta sublimação tem a função de auxiliar a autora a suportar as dificuldades de sua vida. Ou seja, a consciência da vulnerabilidade permanece como pano de fundo: Carolina ainda está no barraco imundo, tudo ainda está impregnado do fedor do lixo, os filhos dormem com fome, mas a escrita a empodera de tal modo que ela pode, ao dizer do sofrimento, partilhá-lo e suportar a vida com resignação.

A sua escrita é também atravessada por um quarto elemento: uma reflexão sobre a fome. No primeiro livro, a fome é representada de maneira mais direta e rude. 
Não há dinheiro, quando chove não há condições de catar papel, ela emagrece oito quilos, os filhos estão sempre sujos e pedem coisas que ela simplesmente não pode ofertar. Em Casa de alvenaria, a fome toma outras proporções: há um vigor analítico e social mais poderoso, e isto é sintoma da consciência de que aquele livro, feito já por encomenda, tem um público certo e apesar de, em inúmeros momentos, ela se referir a favelados e negros como seres completamente exteriores à sua realidade, ela compreende que é a sua voz que poderá dizer de seus sofrimentos. Assim, a fome se transveste, primeiro em saciedade:

- Sabe, mamãe, eu vou dizer uma coisa para a senhora.

- Que é? - perguntei apreensiva, pensando - será uma coisa grave?

- Como é bom a gente comer até encher! (JEsus, 1961, p. 15).

Os filhos e ela passam a ter o que comer, o imediato da fome é satisfeito, mas a precariedade se espalha por todos os cantos. Depois, ela aponta a influência da fome na construção subjetiva das pessoas a partir da observação de seu próprio filho, afirmando que o seu comportamento mudou, ele deixa de ser bruto e passa a ser "João Gentil", e analisa: "a fome deixa as pessoas neuróticas" (Jesus, 1961, p. 16). A fome também aparecerá na rotina torturante, através da romaria de pessoas conhecidas e desconhecidas que vem lhe pedir dinheiro. Agora, a fome transvestese na necessidade do outro, apresenta-se como um desfile de miseráveis à sua porta, o que instaura um permanente incômodo: "9 de Fevereiro Hoje ninguém veio me pedir dinheiro. Graças a Deus” (Jesus, 1961, p. 137).

A fome igualmente aparecerá na ambivalência resultante de seu tão acalentado sonho de ter uma casa de alvenaria. Ela compra a casa, indicada por Audálio Dantas, e, quando vai se mudar, às vésperas do Natal de 1960, a casa ainda está ocupada. Ela se muda sem avisar e convive por muito tempo com a família que ali residia, e a adaptação à casa não é fácil:

\footnotetext{
8 de janeiro

Levantei furiosa, xingando a minha vida. Estou descontente com esta casa. Olho as paredes, estão sujas. Olho o jardim, está triste porque não tem flor. O quarto onde estão as coisas dos nortistas está superlotado de pulgas. [...] Xinguei o reporter. Aquele cachorro podia comprar uma casa limpa para mim (JesUs, 1961, p. 125).

6 de março

Estou lutando para ageitar-me dentro da casa de alvenaria. E não consigo. Minhas impressões desta casa de alvenaria variam. Tem dia que estou no céu, tem dia que estou no inferno, tem dia que eu penso ser a Gata Borralheira (JEsus, 1961, p.151).
}

Ao mudar-se para a casa de alvenaria, Carolina confronta-se com a precariedade da casa, com a falta de beleza, a sujeira, enfim, a fome agora é outra: ela se representa pela impossibilidade constante de viver em plenitude. 
A relação com o jornalista azeda com o tempo. Ela se sente escravizada por ele, que gerencia seu dinheiro, assinando os cheques que ela utiliza no dia a dia, inviabilizando a exploração de outros dotes artísticos - que iam do canto à composição - e, principalmente, a possibilidade de uma construção estética para além do diário:

RF: Houve algum tipo de instrução por parte do senhor ou de outros intelectuais, artistas como Paulo Dantas em relação a composição, organização ou sugestões para escrita de Carolina de Jesus?

AD: Não. A minha discussão com ela se restringia ao tipo de coisa que ela escrevia. Eu acho que o grande valor dos textos da Carolina está exatamente nos diários porque eles constituem documentos importantes. Ao mesmo tempo em que revelam sua capacidade de pensar, de observar o mundo e descrever as coisas que vê. Porque acho que contos, romances, poesias podem ter - evidentemente têm importância por ser ela a pessoa que era -, mas do ponto de vista de interesse mesmo eu acho que são os diários. Aliás, eu desaconselhei que ela editasse poesia e provérbios, essas coisas... Ela fez tudo isso por conta dela (DANTAS, 2014).

Aqui chegamos ao quinto e último elemento que destacaria desta escrita da precariedade: a consciência de que o livro é um instrumento poderoso. No entanto, ele é, como toda escrita, um Pharmakon (DERRIDA, 2005), carrega consigo a interface veneno-remédio. No tocante ao aprisionamento a um único modelo de escrita, Carolina passaria, no que dependesse do jornalista e da editora, a ser fornecedora permanente de cotas de miséria cotidiana para a classe média brasileira. Ou seja, ela não era reconhecida como escritora, este lugar a ela era negado. Era uma narradora, quase uma infiltrada numa realidade que se quer manter longe. E ela não seria jamais alçada ao lugar de escritora simplesmente porque o lugar simbólico de escritor não poderia ser ocupado por ela, uma mulher negra, semialfabetizada, favelada. O cinturão invisível que impediu o acesso a este lugar não se enfraqueceu jamais, deixando à margem seus poemas, contos, composições, enfim, ela não era uma escritora, era uma favelada que escrevia.

Mesmo reduzida a este lugar, havia limites para a sua construção estética. Ela poderia dizer tudo, mas jamais de maneira rebuscada, bem como era vista por muitos como uma mulher arrogante. A sua escrita igualmente sofria com a reatividade dos que tinham certa expectativa estereotipada dela:

19 de outubro

...Alguns criticos dizem que sou pernostica quando escrevo - os filhos abluíram-se - Será que preconceito existe até na literatura? O negro não tem direito de pronunciar o classico? (Jesus, 1961, p. 63-64).

23 de novembro

Não estou tranquila com a ideia de escrever o meu diario da vida atual. Escrever contra os ricos. Eles são poderosos e podem destruir-me (Jesus, 1961, p. 83). 
Certa feita, quando perguntada numa entrevista como ela se sentia no "apogeu", ela respondeu sem pestanejar: "sinto-me confusa". A história do "era uma vez uma preta que morava no inferno. Saiu do inferno e foi para o céu” (JEsUs, 1961, p. 171) não durou o suficiente. $\mathrm{O}$ dinheiro acabou, as publicações e vendas minguaram, e Carolina retornou para a favela.

A compreensão corrente de literatura e de sua função para o escritor é de que ela é uma via para preencher a lacuna, retirar do sujeito e daqueles que leem a sensação de carência e incompletude. Carolina de Jesus instaura um violento corte nesta tradição. A sua escrita não consola, não apazígua; ela forja outra possibilidade de poética. Se entendermos esta palavra como a formação de uma dicção de escrita que insta o crítico a buscar instrumentais com os quais possa abordar o texto, se a poética da fome, como aqui denominamos, reorganiza as formas de representação do sujeito subalternizado, se ela instaura uma ruptura na gramática, se ela toma para si uma verve analítica, podemos sim defender que a escrita de Carolina exige outros percursos de pensamento.

Ela oferta aos leitores e estudiosos uma escrita da precariedade que se manifesta não apenas nos cinco traços aqui elencados, mas que se sintomatiza na forma: há dias seguidos em que a narrativa se resume a uma frase, o que instaura uma fragmentação e, ao mesmo tempo, a lacuna como complexidade a ser analisada; seus textos não são desvestidos de figuras de linguagem, no entanto, não se aprisionam a eles, derrubando o crítico que busca, na análise literária, o mero volteio de linguagem; a palavra fome, repetida à exaustão, deixa-nos nauseados. Ao repetir e fazer com que ela se performatize em várias faces, ela recoloca a fome, não apenas como questão social, mas como metodologia de construção discursiva, como meio, não de esvaziamento, mas de enraizamento do sujeito. A fome não é alegórica, e pela força de sua capacidade de organizar a vida de milhares de pessoas, sintetizadas em Carolina Maria de Jesus, a fome é, em si, o sentimento da precariedade.

\section{Referências}

Abreu, Márcia. Cultura letrada: literatura e leitura. São Paulo: Unesp, 2006.

Barthes, Roland. A morte do Autor (1968). In: Barthes, Roland. O rumor da língua. São Paulo: Martins Fontes, 2004. Disponível em: https://bit.ly/2w77Kb2. Acesso em: 15 maio 2015.

BhabHa, Homi K. O local da cultura. Tradução de Myriam Ávila, Eliana Lourenço de Lima Reis e Gláucia Renate Gonçalves. Belo Horizonte: Editora da UFMG, 1998.

Dantas, Audálio. Entrevista a Raffaela Fernandez. Scripta, Belo Horizonte, v. 18, n. 35, p. 305-314, 2014.

De Bruyne, Edgar. Esquisse d'une philosophie de l'art. Bruxelles: Librairie Albert Dewit, 1930 
Derrida, Jacques. A farmácia de Platão. Tradução de Rogério da Costa. São Paulo: Iluminuras, 2005 .

FAnON, Frantz. Pele negra, máscaras brancas. Tradução de Renato da Silveira. Salvador: Editora da UFBA, 2008.

Foucault, Michel. A escrita de si. In: Foucault, Michel. O que é um autor? Lisboa: Passagens, 1992. p. 129-160.

Foucault, Michel. História da loucura. São Paulo: Perspectiva, 2008.

Jesus, Carolina Maria de. Quarto de despejo. São Paulo: Ática, 1993.

Jesus, Carolina Maria de. Casa de alvenaria. Rio de Janeiro: Paulo de Azevedo, 1961.

LeJeune, Philippe. O pacto autobiográfico: de Rousseau à internet. Tradução de Jovita Maria Gerheim Noronha e Maria Inês Coimbra Guedes. Belo Horizonte. Editora da UFMG, 2008. (Coleção Humanitas).

Nietzsche, Friedrich. Segunda consideração intempestiva. Da utilidade e desvantagem da história para a vida. Tradução de Marco Antônio Casanova. Rio de Janeiro: Relume Dumará, 2003.

Pinho, Osmundo. Lutas culturais: relações raciais, antropologia e política no Brasil. Sociedade e Cultura, Goiás, v. 10, n. 1, p. 81-94, jan./jun. 2007. Disponível em: https://www.revistas.ufg.br/fchf/article/view/286. Acesso em: 10 maio 2015.

SouzA, Eneida Maria de. Crítica cult. Belo Horizonte: Editora da UFMG, 2002.

SPIVAK, Gayatri Chakravorty. Pode o subalterno falar? Belo Horizonte: Editora da UFMG, 2010.

Recebido em 14 de fevereiro de 2018.

Aprovado em 3 de abril de 2018.

\section{Resumo/Abstract/Resumen}

A poética da fome e a escrita da precariedade: sobre Carolina Maria de Jesus

\section{Lívia Natália}

Defendemos aqui que a escrita de autoras negras, com destaque para Carolina Maria de Jesus, investe no acionamento de formas de representação literária que engendram, pela sua diç̧ão estética, formas específicas de representação de mundo. Na medida em que estas escritas se forjam, emergem conceitos que são potentes para analisar o seu modo e percurso de criação, aqui, damos destaque à dimensão 
biográfica como um valor estético na literatura de Carolina Maria de Jesus a partir dos conceitos de poética da fome e a escrita da precariedade, aqui apresentados.

Palavras-chave: poética da fome, escrita da precariedade e dicção estética.

The poetics of hunger and the writing of precarity: about Carolina Maria de Jesus

\section{Lívia Natália}

In this text we state that black women's writing, highlighting Carolina Maria de Jesus, invest in the indexation of forms of literary representation which, due to its aesthetic diction, engender specific forms of world representation. Insofar as these writings are forged, potent concepts to analyze its literary writing process emerge. We call attention to the biographical dimension as an aesthetic value in Carolina Maria de Jesus's literature based on the concepts of poetics of hunger and writing of precarity presented here.

Keywords: poetics of hunger, writing of precarity, aesthetic diction.

\section{La poética del hambre y la escritura de la precariedad: sobre Carolina Ma-} ria de Jesus

\section{Lívia Natália}

Defendemos aquí que la escritura de las mujeres negras, destacando a Carolina Maria de Jesus, apuesta por el uso de formas de representación literaria que, debido a su dicción estética, engendran formas específicas de representación del mundo. En la medida en que estos escritos se forjan, emergen potentes conceptos para analizar su proceso de creación. Llamamos la atención sobre la dimensión biográfica como un valor estético en la literatura de Carolina Maria de Jesus a partir de los conceptos de la poética del hambre y la escritura de la precariedad aquí presentados.

Palabras clave: poética del hambre, escritura de la precariedad, dicción estética. 